rev.relac.int.estrateg.segur.5(2):195-210,2010

\title{
LOS EJES DE LA POLÍTICA DE DEFENSA ESTADOUNIDENSE EN LA POSGUERRA FRÍA
}

\author{
Guillem Colom Piella*
}

The first priority is to speed the transformation of our military. When the Cold War ended, some predicted that the era of direct threats to our nation was over. Some thought our military would be used overseas - not to win wars, but mainly to police and pacify, to control crowds and contain ethnic conflict. They were wrong. While the threats to America have changed, the need for victory has not. We are fighting shadowy, entrenched enemies - enemies using the tools of terror and guerrilla war - yet we are finding new tactics and new weapons to attack and defeat them. This revolution in our military is only beginning, and it promises to change the face of battle.

Presidente George W. Bush Ciudadela de Charleston (Carolina del Sur)

11 de Diciembre de 2001

Licenciado en Sociología y en Ciencia Política por la Universidad Autónoma de Barcelona (UAB), Master, Diploma de Estudios Avanzados y candidato a Doctor en Relaciones Internacionales por la misma universidad, y Doctor en Paz y Seguridad Internacional por el Instituto Universitario General Gutiérrez Mellado. Profesor de Ciencia Política en la Universidad Pablo Olavide y de Estudios Estratégicos en el Instituto Universitario General Gutiérrez Mellado, y colaborador de la Escuela Superior de las Fuerzas Armadas españolas. guillemcolom@hotmail.com 


\title{
RESUMEN
}

El artículo estudia la Revolución Americana en los Asuntos Militares, eje del planeamiento estratégico estadounidense de la inmediata posguerra fría, promotora de su proceso de Transformación militar y responsable de los logros iniciales y de los fracasos posteriores en las largas campañas de Afganistán e Irak.

Palabras clave: Revolución en los Asuntos Militares, Transformación, Fuerzas Armadas, Estados Unidos, Política de Defensa, Política Militar

\begin{abstract}
The article analyses the American Revolution in Military Affairs, an idea which not only articulated the U.S. post-Cold War strategic planning and was the key promoter of its process of military Transformation, but it is also the main responsible for its initial successes and later failures in the protracted Afghan and Iraqi campaigns.
\end{abstract}

Key words: Revolution in military affairs, transformation, armed forces, The United States of America, defence policy, political military

\section{INTRODUCCIÓN}

La espectacular victoria cosechada por la coalición encabezada por Estados Unidos en la Guerra del Golfo de 1991 popularizó una idea que hasta entonces se había debatido en secreto en las más altas esferas de Washington y de Moscú: la posible existencia de una Revolución en los Asuntos Militares (Revolution in Military Affairs - RMA) capaz de transformar el arte de la guerra.

El alcance, características y posibles consecuencias de esta revolución que prometía acabar con el paradigma militar contemporáneo no sólo fascinó a militares, políticos y académicos de todo el mundo; sino que Estados Unidos propuso aprovechar la aparente paz que estaba disfrutando la humanidad tras la caída del Telón de Acero para lograr la RMA con el fin de mantener su supremacía militar frente a cualquier adversario futuro.

Aunque pronto la búsqueda de esta codiciada revolución ocupó un destacado lugar en la configuración de los pilares estratégicos del país para la posguerra fría y su conquista centró su proceso de planeamiento de la defensa, fue la entrada de George W. Bush en la Casa Blanca el factor definitivo para la consolidación de la RMA. Dispuesto a terminar con las inercias políticas, militares e industriales de la Guerra Fría; decidido a formular una política de seguridad, defensa y militar apropiada al nuevo concierto internacional y resuelto a conquistar la revolución duran- 
te su mandato, planteó un ambicioso programa de Transformación del entramado de defensa del país para acomodarlo al nuevo milenio.

Los trágicos sucesos del 11 de Septiembre de 2001 pusieron de manifiesto la urgencia de adaptar el poder militar estadounidense a los múltiples y heterogéneos retos que planteaba el mundo del siglo XXI, y la invasión de Afganistán e Irak permitieron poner en práctica las capacidades desarrolladas años atrás para conquistar la RMA y evaluar la viabilidad de la gran estrategia diseñada por Estados Unidos para mantener su hegemonía internacional en la posguerra fría.

Sin embargo, las largas campañas afgana e iraquí han revelado el cambiante rostro de la guerra y mostrado tanto las cualidades como los límites de este modelo militar derivado de la RMA; lo que está obligando a revisar los pilares estratégicos de Estados Unidos con objeto de enfrentarse con éxito a los requerimientos presentes y futuros.

El presente artículo analizará este conjunto de cambios producidos en la política de defensa estadounidense desde el fin de la Guerra Fría hasta el cambio de rumbo que está tomando hoy en día el proceso de Transformación militar del país.

\section{LA REVOLUCIÓN ESTADOUNIDENSE EN LOS ASUNTOS MILITARES}

Durante la década de los noventa, el planeamiento de la defensa estadounidense estuvo condicionado por la configuración de los pilares estratégicos del país para la posguerra fría y la búsqueda de la RMA, una revolución que prometía dotar a sus fuerzas armadas de la supremacía militar frente a cualquier posible adversario futuro.

Aunque en la actualidad la RMA continúa siendo un controvertido concepto sujeto a múltiples interpretaciones, los analistas de defensa tienden a definirla como un profundo cambio en la forma de luchar que resulta de la integración de nuevas tecnologías, conceptos operativos, estilos de mando o modelos de organización en las fuerzas armadas (Shimko, 2010). Esta transformación convierte en irrelevante u obsoleto el paradigma militar pre-revolucionario y proporciona una enorme superioridad al primer ejército que explota estas capacidades. Es por esta razón que cualquier posible adversario deberá alcanzar este nuevo catálogo de capacidades, bien sumándose a la revolución o desarrollando una respuesta que pueda acabar con dicha ventaja (Galdi, 1995 o Gray, 2002).

Aunque a lo largo de la historia se han producido un sinfín de revoluciones que han transformado la forma de concebir la guerra y combatir en ella (Knox y Murray, 2001); la que articulará el presente trabajo empezó a gestarse a mediados de la década de los setenta coincidiendo con el fin de la Guerra de Vietnam. Esta contienda reveló las carencias del ejército estadounidense, proyectado, organizado, adiestrado y equipado para enfrentarse a la Unión Soviética en un 
conflicto convencional o nuclear; y manifestó los límites del tradicional estilo militar americano, de corte logístico y orientado al desgaste del enemigo (Weigley, 1977). Su fatal desenlace produjo profundos cambios en la arquitectura defensiva del país con objeto de recuperar la iniciativa estratégica perdida y enfrentarse con garantías de éxito a una Unión Soviética cada vez más poderosa (Kagan, 2006) ${ }^{1}$.

Continuó desarrollándose en el frente central europeo cuando, para afrontar la erosión del equilibrio nuclear entre las dos superpotencias, Estados Unidos propuso mejorar sus capacidades convencionales con una ambiciosa estrategia que incluía tanto la adopción de nuevos conceptos e ideas como la integración de los primeros productos de la revolución de la información en nuevas plataformas, sensores y armas. El impacto de esta maniobra fue tal que los estrategas soviéticos no dudaron en considerarla como una Revolución Técnico-Militar que, debida al impacto de los nuevos «complejos de ataque automatizados» (nombre que emplearon para definir la integración de los sistemas de mando, control y comunicaciones y armas de precisión), podría acabar con el precario equilibrio estratégico que existía entre ambas superpotencias en Europa (Cohen, 1996).

Esta idea captó el interés del analista de defensa estadounidense Andrew Marshall, que la articuló conceptualmente (juzgó que la tecnología debía combinarse con cambios organizativos, doctrinales y conceptuales); identificó las tecnologías revolucionarias (el armamento de precisión e inteligente, los sistemas de Mando, Control, Comunicaciones, Ordenadores, Inteligencia, Observación y Reconocimiento (C $\left.{ }^{4} \mathrm{ISR}\right)$ y las plataformas furtivas); propuso su denominación definitiva (Revolución en los Asuntos Militares) y expuso las potencialidades de la revolución (la obtención de un completo, transparente y permanente conocimiento del teatro de operaciones, un efectivo mando y control de las fuerzas que allí operan y precisos ataques sobre los objetivos enemigos, logrando así victorias rápidas, decisivas y sin apenas daños colaterales). Además, valiéndose de su influyente posición dentro del Departamento de Defensa americano, intentó promoverla entre la clase política y militar del país (Iklé y Wohlstetter, 1988)². Sin embargo, el éxito que obtuvo fue muy limitado, pues a finales de los ochenta el Pentágono estaba más

1 Entre las transformaciones militares que Estados Unidos acometió para superar la debacle vietnamita cabe citar el diseño de una nueva estrategia global, la imposición de un modelo de recluta voluntario, la integración de las fuerzas regulares, de reserva y la Guardia Nacional en una Fuerza Total, la renovación de los pilares de su pensamiento militar y el arranque de un ambicioso proceso de modernización de armamento y material que se ha dilatado hasta nuestros días.

2 En la segunda mitad de los ochenta se constituyeron varios grupos de trabajo con objeto de dilucidar si los cambios que se estaban produciendo en la esfera militar podían transformar el arte de la guerra y cómo se debía proceder para lograr la revolución. El más influyente congregó a expertos de la talla de Albert Iklé (Subsecretario de Defensa de 1981 a 1988), Albert Wohlstetter (estratega nuclear), Zbiniew Brezinski (Consejero de Seguridad Nacional de 1977 a 1981), Henry Kissinger (Secretario de Estado de 1973 a 1977), Samuel Huntington (profesor e investigador) o Andrew Marshall (impulsor de la RMA). 
preocupado en adaptar el entramado defensivo del país a la década de los noventa que en plantearse la existencia de una revolución militar capaz de transformar la guerra.

Los resultados preliminares de estas transformaciones se manifestaron durante la Guerra del Golfo de 1991, cuando la coalición liderada por Estados Unidos logró una espectacular victoria frente a Irak. Aunque ello catapultó esta idea al centro del análisis estratégico internacional, el Departamento de Defensa americano mostró un limitado interés por esta posibilidad, pues en aquellos momentos de euforia su máxima prioridad era articular los pilares estratégicos del país a la inmediata posguerra fría. Sólo sus fuerzas armadas se sumaron a las discusiones, atraídas por los efectos que podría tener esta posible revolución sobre su forma de lucha y porque podían utilizar la RMA como arma política en sus férreas pugnas internas por los recursos y el poder en una coyuntura marcada por la crisis financiera y el cobro del dividendo de la paz (Larson et alt., 2001).

A mediados de la década, coincidiendo la propagación de la euforia revolucionaria entre las élites política y militar del país, el Almirante William Owens - Vicepresidente de la Junta de Jefes de Estado Mayor entre 1994 y 1996 - identificó la esencia de la RMA: el sistema de sistemas o la capacidad que tendría cualquier sensor, plataforma, combatiente o arma para interactuar con el resto gracias a su integración en red. Owens sostenía que los fundamentos tecnológicos de la RMA ya existían, pues eran el resultado de décadas de inversiones millonarias para hacer frente a la Unión Soviética. Sin embargo, lo realmente revolucionario era la integración de todos los elementos de la fuerza en un sistema de sistemas que proporcionara información, casi a tiempo real, de todo lo que sucede en el campo de batalla y batir con precisión prácticamente cualquier objetivo desde grandes distancias y sin apenas daños colaterales. Ello abría paso a una revolución en el arte militar, pues el Almirante aseguraba que por primera vez en la historia se disiparía la niebla de la guerra persistente en todas las batallas desde la antigüedad (Owens, 2000).

Para conquistar esta revolución se juzgó vital adquirir las novedosas tecnologías propias de la Era de la Información (modernas plataformas, avanzados sensores y sofisticadas armas, convenientemente integradas en red creando un sistema de sistemas) e implementar nuevas formas de actuación (impulso de la acción conjunto-combinada, operaciones basadas en efectos, orientación expedicionaria y guerra en el espacio, ciberespacio y en la esfera de la información); nuevos modos de organización (adelgazamiento y flexibilización de estructuras, integración horizontal, orgánicas flexibles, modulares y optimizadas para una rápida proyección, eficaz sostenimiento y autonomía de acción en toda la gama de las operaciones), estándares de adiestramiento (aumento de la instrucción y preparación de los combatientes para asumir mayores responsabilidades, desempeñar nuevas tareas y emplear sofisticados sistemas) y estilos de conducción de las operaciones (descentralización del mando, nueva organización de los Estados Mayores, mayor control estratégico y político de las operaciones militares e integración de la cadena de mando militar en operaciones interagencia) (Friedman, 1998). 
Y para financiar las vastas transformaciones tecnológicas, estructurales, procedimentales y orgánicas requeridas para lograr la RMA, se estimó necesario promover una Revolución en los Asuntos de Negocios (Revolution in Business Affairs - RBA) que, fundamentada en la aplicación de economías de escala, la centralización de los procesos de obtención de armamento y material, la simplificación y flexibilización de los trámites administrativos, el empleo de tecnologías duales o la externalización de ciertos servicios, permitiera optimizar la gestión de la defensa y garantizar los fondos necesarios para sufragar la revolución (Lippitz y White, 2001).

También fue en esta coyuntura marcada por la euforia revolucionaria cuando el Pentágono, que se hallaba ocupado construyendo los pilares defensivos de la nación para la posguerra fría, no sólo consideró utilizar algunas de las posibilidades que brindaba la RMA para resolver ciertos interrogantes estratégicos que debía afrontar el país (como mantener la estrategia de luchar en dos conflictos regionales de manera simultánea con una estructura de fuerzas sensiblemente menor que la mantenida durante la Guerra Fría); sino también empezó a plantearse seriamente la existencia de esta revolución que juzgaba vital para conservar tanto la supremacía militar como la hegemonía política del país en el nuevo milenio (O'Hanlon, 1995).

En el año 1996, la cúpula militar estadounidense adoptó formalmente la RMA con la edición de la Joint Vision 2010. Este trabajo avalaba su existencia, fijaba los pilares y elementos definidores de esta revolución para Estados Unidos - donde el dominio de la maniobra, la precisión en el combate, la protección multidimensional y la logística focalizada, aglutinadas mediante la superioridad en la información, constituían los elementos necesarios para triunfar en todos los conflictos - las capacidades futuras de sus fuerzas armadas y el camino a seguir para conquistar esta revolución que prometía inaugurar un nuevo estilo americano de combatir.

Este trabajo permitió establecer un enfoque conjunto sobre los pilares y objetivos de la RMA estadounidense, proporcionó a los ejércitos unas líneas maestras comunes pero lo suficientemente vagas como para que continuaran desarrollando e implementando sus planteamientos específicos y sentó las bases para la aceptación de la revolución en el ámbito político, un hecho que se produciría un año después.

En efecto, en 1997 la Administración Clinton presentó la primera Revisión Cuadrienal de la Defensa (Quadrennial Defense Review). Este trabajo, base de la política de defensa y militar del país para la legislatura 1996-2000, no sólo aceptaba la existencia de la RMA y apadrinaba los pilares de la misma identificados por la cúpula militar, sino que entendía que su explotación era uno de los hitos para afrontar con garantías de éxito los peligros futuros y contribuir al mantenimiento de la hegemonía americana en el nuevo concierto internacional.

Y para tal fin, el Pentágono propuso aprovechar la aparente pausa estratégica que estaba viviendo el mundo para desarrollar e implementar las capacidades revolucionarias, acomodar la estructura militar del país a los riesgos futuros y modernizar los sistemas heredados de la Guerra 
Fría para mantener fuerzas suficientes para combatir en cualquier conflicto que pudiera materializarse mientras se diseñaba el ejército del siglo XXI. Este proceso encaminado a lograr la revolución y preparar la arquitectura de seguridad y defensa estadounidense para los riesgos y amenazas que podrían materializarse en las primeras décadas del nuevo siglo recibió el nombre de Transformación (Roxborough, 2002).

Aunque la Revisión Cuadrienal de la Defensa consideraba vital que Estados Unidos transformara su puño militar para lograr la RMA y prepararse para un futuro incierto, la baja dotación presupuestaria para el desarrollo y adquisición de nuevas capacidades (el objetivo de gasto propuesto por la revisión nunca se alcanzó) y la elevada participación de sus fuerzas armadas en operaciones de apoyo a la paz y gestión de crisis (que, ante la negativa de un Congreso y Senado controlados por el Partido Republicano a asignar partidas extraordinarias para financiar estas labores, tuvieron que sufragarse con los fondos inicialmente destinados a la modernización de material y al adiestramiento de las unidades), paralizaron el proceso de transformación (Larson et alt., 2001).

No obstante, la llegada de George W. Bush a la Casa Blanca supuso el impulso final y definitivo a la RMA. Cautivados por estas ideas y conscientes del importante papel que tendría esta revolución en la configuración del orden mundial del nuevo milenio ${ }^{3}$, el Presidente Bush y su Secretario de Defensa Rumsfeld trazaron un ambicioso proceso de transformación que, presentado formalmente en la Revisión Cuadrienal de la Defensa de 2001, pretendía conquistar la revolución y preparar la defensa del país a los retos que debería hacer frente en el 2020 (Kitfield, 2005). Para tal fin, no sólo propusieron una estrategia de seguridad, defensa y militar adecuada al nuevo ambiente estratégico, sino que situaron la transformación del conjunto de la defensa estadounidense (desde la estructura, volumen, equipamiento y capacidades de sus fuerzas armadas hasta la organización, funcionamiento, administración y finanzas del Departamento de Defensa) como una de las prioridades políticas del nuevo Gobierno (Rumsfeld, 2002).

Aunque inicialmente considerada como el medio para alcanzar la RMA, pronto la transformación se convirtió en el objetivo a corto, medio y a largo plazo del planeamiento de la defensa norteamericano (Binnendijk, 2002). Y es que junto con la fascinación del Secretario de Defensa Donald Rumsfeld por esta idea, los sucesos del 11 de Septiembre de 2001 terminaron repentinamente con la pausa estratégica iniciada con el fin del mundo bipolar, convencieron a Estados Unidos de la urgencia de adaptar su arquitectura de seguridad al nuevo ambiente estratégico, aceleraron su proceso de transformación militar y le permitieron poner en práctica la ansiada revolución (Colom, 2008).

3 Además de los numerosos discursos y comparecencias del Presidente Bush, el Secretario Rumsfeld y el Subsecretario Wolfowitz, es interesante la lectura del programa de defensa del flamante inquilino de la Casa Blanca poco después de su nombramiento, enteramente dedicado al proceso de transformación (Bush, 2001). 


\section{EL BAUTISMO DE FUEGO DE LA REVOLUCIÓN: AFGANISTÁN E IRAK}

Los ataques sobre Nueva York y Washington conmocionaron al mundo y provocaron la inmediata reacción de Estados Unidos, que optó por responder a los atentados invadiendo Afganistán para derrocar al régimen Talibán, detener a los responsables de los atentados y acabar con este santuario terrorista. La invasión y ocupación de este país centroasiático despertaba enormes temores en la comunidad de defensa estadounidense, pues una década antes este país había derrotado al gigante soviético. Sin embargo, Rumsfeld estaba convencido de que este escenario era idóneo para probar la maquinaria militar del país, ensayar el estilo bélico fruto de la revolución y catapultar el proceso de transformación. En consecuencia, desechó los conservadores planes presentados por los estrategas militares y se aferró a la propuesta realizada por la CIA que, basada en la provisión de apoyo aéreo, económico y militar a las tribus locales para que apoyaran la intervención americana, le permitiría validar el nuevo estilo de combatir. Sin embargo, el Presidente Bush finalmente aprobó un plan de operaciones más moderado que el presentado por su Secretario de Defensa que integraba ambos enfoques pero mantenía los erróneos supuestos y ambiguos objetivos políticos de ambos planteamientos (Woodward, 2002) ${ }^{4}$.

En Octubre de 2001 arrancó la Operación Libertad Duradera con el bombardeo de varios objetivos estratégicos y la incursión de pequeñas unidades de operaciones especiales, infantería ligera y equipos de la CIA apoyados por la fuerza aérea y la Alianza del Norte, una coalición de clanes rivales unidos por su origen mayoritariamente no-Pashtun y su odio a los talibanes. Después de varias semanas de cruentos combates entre las fuerzas de la coalición y las milicias talibanes, el régimen afgano se desmoronó y los talibanes se refugiaron en las montañas del país y en el vecino Pakistán, las fuerzas de la coalición entraban triunfantes en Kabul y Hamid Karzai era designado Presidente de la nueva Autoridad Provisional Afgana.

La fulminante victoria lograda por esta extraña coalición de conveniencia asombró al mundo y sorprendió a la comunidad de defensa americana, que no dudó en afirmar que las tecnologías (sistemas no-tripulados, comunicaciones por satélite, equipos de navegación y posicionamiento o armas inteligentes); procedimientos (guerra en red, plena integración aeroterrestre, operaciones basadas en efectos o dominación rápida) y orgánicas (una pequeña fuerza combinada e interagencia constituida ad-hoc para la misión) empleadas durante la invasión de Afganistán eran signos inequívocos de que la RMA estaba en marcha, por lo que aconsejaron acelerar el proceso de transformación militar (Biddle, 2004).

\footnotetext{
4 Este plan no sólo sobreestimaba la capacidad militar afgana, olvidaba que el gobierno talibán ni controlaba el territorio ni gozaba del apoyo popular y descuidaba el hecho que ninguno de los clanes enfrentados a los talibanes y con objetivos políticos muy distintos a los americanos era suficientemente poderoso como para gobernar el país de forma individual; sino que evitaba plantearse cómo debería ser el país depuesto el régimen talibán, obviaba completamente su estabilización y reconstrucción o desechaba la oportunidad que se presentaba a Estados Unidos de luchar contra Al Qaeda en terreno abierto (Kagan, 2006).
} 
En efecto, la Operación Libertad Duradera derrocó el régimen talibán y alteró el entramado terrorista de Al Qaeda en Afganistán pero no logró capturar a Osama Bin Laden o el Mullah Omar, dos de los máximos objetivos de la campaña militar. Además, el reducido volumen de tropas empleado para invadir el país; su deficitaria preparación en labores de seguridad, contrainsurgencia o estabilización y reconstrucción e incapacidad para ejercer un control efectivo del territorio y la inexistencia de un plan coherente para su pacificación, facilitaron el estallido de una feroz campaña insurgente que ha continuado hasta fecha de hoy a pesar de los importantes esfuerzos de la comunidad internacional para pacificar el país. Ello ha convertido a Afganistán en un problema de difícil solución y en uno de los máximos quebraderos de cabeza del Presidente Obama, de la Alianza Atlántica y de todos los países que mantienen presencia militar en este avispero.

Sin embargo, a principios de 2002 la situación parecía completamente distinta, por lo que la Administración republicana - convencida de que la campaña afgana había sido un éxito militar, diplomático y político absoluto - procedió a trasladar estos preceptos en el planeamiento para invadir Irak (Bardají, 2002).

Los planes iniciales no distaban mucho de la Operación Tormenta del Desierto de 1991, pues se basaban en el despliegue de una enorme fuerza, una campaña aérea para erosionar la resistencia iraquí y una incursión terrestre desde el norte y el sur del país hasta conquistar Bagdad. Sin embargo, Donald Rumsfeld desechó estos planes por conservadores, pues el despliegue y concentración de fuerzas sería lento, acarrearía grandes costes políticos y lastraría las maniobras diplomáticas del país. Determinado a superar las inercias históricas y acabar definitivamente con la restrictiva y obsoleta doctrina Weinberger-Powell - que imponía severas limitaciones al empleo del poder militar y debilitaba la capacidad de maniobra política del país al recomendar el empleo de la fuerza armada como último recurso, de forma aplastante y con objetivos claramente definidos - Rumsfeld propuso aplicar su revolucionario modelo e ir a la guerra con una fuerza mucho menor (Woodward, 2002).

Después de varias tentativas infructuosas y numerosas controversias entre la cúpula militar y política sobre la estrategia a seguir y el volumen de fuerzas a emplear en la invasión de Irak (que comprendían desde los 85.000 efectivos propuestos inicialmente por Rumsfeld a los 500.000 requeridos por las autoridades militares), el Mando Central estadounidense presentó un sofisticado plan de operaciones que obtuvo la aprobación del Secretario de Defensa. La invasión del país correría a cargo de una fuerza - cuantificada en 300.000 efectivos - que se desplegaría a Oriente Medio para iniciar de inmediato las operaciones militares, articuladas en torno a una campaña de «choque y pavor» (Shock \& Awe) mediante ataques contra los centros de gravedad iraquíes y la simultánea penetración terrestre para conquistar rápidamente Bagdad, pues el principal objetivo de la campaña no era acabar con el ejército iraquí sino paralizar el país, tomar la capital y derrocar el régimen antes de que Hussein pudiera llevar a cabo alguna represalia contra las fuerzas de la coalición. Alcanzados los objetivos militares, el plan terminaba con la estabiliza- 
ción del país y el establecimiento de las precondiciones necesarias para la instauración del nuevo régimen político, momento en que la fuerza militar transferiría su responsabilidad al poder civil (Gordon y Trainor, 2006) $)^{5}$

Finalizado el ultimátum impuesto por Estados Unidos para que Irak accediera a cooperar con la comunidad internacional, el 19 de Marzo de 2003 empezó la Operación Libertad Iraquí con el bombardeo de varios puntos de la capital con la esperanza de liquidar la cúpula del gobierno iraquí y derrocar el régimen sin la necesidad de invadir el país. Fracasado este ataque de decapitación, los ejércitos de la coalición cruzaban la frontera para acabar definitivamente con el dictador. Mientras los aviones de la Fuerza Aérea y la Armada disfrutaban de la supremacía en el aire y batían los centros de gravedad y las concentraciones de tropas enemigas a voluntad, las fuerzas mecanizadas del Ejército y el Cuerpo de Marines penetraban desde el sur camino a Bagdad y las unidades ligeras y de operaciones especiales liberaban el Kurdistán iraquí

Un mes después de iniciarse la campaña militar, la coalición había ocupado el país, tomado la capital y derrocado el régimen baathista ${ }^{7}$. Cuando el Presidente Bush anunció el fin de las hostilidades, una irrefrenable euforia se apoderó de la sociedad americana, pues Irak parecía haber ratificado el alcance y efectos de la revolución y la buena marcha de la transformación. Prácticamente nadie pensaba que esta situación podría torcerse tal y como sucedió poco después.

Exacto, los estrategas estadounidenses estimaron que la espectacular victoria frente a Irak había confirmado las enormes cualidades del nuevo estilo militar. Las plataformas, sensores y sistemas de armas desplegados (que comprendían desde los más veteranos equipos heredados de la Guerra Fría hasta los más modernos sistemas $C^{4}$ ISR), los procedimientos empleados (operacio-

5 Aunque el Mando Central entendió que su responsabilidad terminaba con la estabilización de Irak, el plan de operaciones presentado al Secretario Rumsfeld contenía una Fase IV que abarcaba la estabilización, recuperación y transición del país consistente en: (1) la eliminación de las bolsas de resistencia, (2) la toma de las infraestructuras vitales, (3) la protección de los prisioneros de guerra, (4) la localización del armamento de destrucción masiva, (5) la asistencia humanitaria de emergencia, (6) el control de los desplazados, (7) el mantenimiento del orden público, (8) el ejercicio de la autoridad militar en los niveles locales, (9) la restauración de los servicios básicos, (10) el apoyo militar a los actores humanitarios, (11) la reparación de las líneas de comunicación vitales, (12) la promoción de la gobernanza iraquí a nivel local, regional y nacional, y por último (13) la asistencia a la reintegración del ejército iraquí (Ricks, 2006).

6 Inicialmente, el plan de operaciones contemplaba emplear la Cuarta División de Infantería para apoyar la invasión desde el norte. Sin embargo, la negativa de Ankara a aceptar su despliegue en suelo turco junto con la inexistencia de fuerzas pesadas enemigas en la zona, comportaron que Estados Unidos desechara este plan y fuera a la guerra con una estructura de fuerzas más ligera que la inicialmente proyectada.

7 Aunque la campaña de «choque y pavor» contra los centros de gravedad del régimen paralizó el país, no logró la inmediata capitulación pretendida por los estrategas americanos. Igualmente, la invasión terrestre tomó Bagdad en veinte días aunque a costa de dilatar en exceso las líneas de suministro, avanzar sin consolidar el territorio o descuidar la retaguardia. 
nes rápidas, decisivas y basadas en efectos) y las formas de organización adoptadas (plena integración en red de una fuerza conjunta terrestre y anfibia con permanente apoyo aéreo) habían dotado al despliegue americano - que en ningún caso sobrepasó los 100.000 efectivos - de un potencial militar sin precedentes en la Historia. Todo ello permitió que esta pequeña fuerza gozara del pleno dominio del espacio de batalla, luchara con una velocidad, empuje y dinamismo nunca vistos hasta la fecha y lograra el «choque y pavor» perseguido por los estrategas estadounidenses, paralizando el régimen iraquí, desarticulando sus sistemas de mando y control, causando una absoluta confusión entre las filas del ejército iraquí, anulando cualquier oposición militar digna de mención y logrando un triunfo fulminante, aplastante y decisivo.

El Pentágono también se sumó al entusiasmo reinante en Estados Unidos. En la primera comparecencia del Secretario de Defensa posterior al cese de las hostilidades, Rumsfeld proclamó que la espectacular victoria, posibilitada por la efectividad de la campaña de «choque y pavor», el elevado ritmo de las operaciones, la plena integración del esfuerzo conjunto, la guerra en red, la precisión de los ataques o la inteligencia a tiempo real, no sólo había demostrado que la revolución estaba a punto de lograrse y que la transformación marchaba por el camino correcto; sino que había enterrado definitivamente el concepto de fuerza decisiva como axioma de la acción militar estadounidense y ratificado la validez del nuevo estilo de hacer la guerra ${ }^{8}$.

En la misma comparecencia, el General Tommy Franks, comandante operacional de la fuerza multinacional, avaló los planteamientos de Rumsfeld y añadió que los aspectos más destacables de la operación habían sido la acción conjunta, el armamento de precisión, la consciencia situacional proporcionada por los sistemas $C^{4} I S R$, la elevada disponibilidad de los equipos empleados o la preparación e iniciativa de las fuerzas de la coalición. El Subsecretario de Defensa Paul Wolfowitz también se sumó al júbilo generalizado existente en el país al declarar que la campaña iraquí había mostrado al mundo los primeros frutos de la RMA, pues el ejército estadounidense - definido por su esfuerzo conjunto, articulación en red, avanzadas plataformas, modernos sensores y poderosos proyectiles inteligentes - logró dominar inmediatamente el espacio de batalla, combatir a un ritmo nunca visto hasta la fecha, atacar las fuerzas y resortes del poder iraquí desde todas las dimensiones, disfrutar de la plena protección del despliegue y conquistar los objetivos de la campaña con una rapidez, decisión y resolución inusitadas ${ }^{9}$.

En conclusión, la fulminante victoria estadounidense en Irak - lograda por una pequeña fuerza dotada de probados materiales, equipada con avanzadas tecnologías y empleada en base a nuevos conceptos operativos - pareció corroborar los primeros frutos de la revolución, la validez de la transformación y la eficacia del nuevo estilo militar americano. Ello no sólo acentuó el exagerado optimismo reinante entre la clase política y militar del país después del sorprendente

8 Comparecencia ante el Comité del Senado para las Fuerzas Armadas, 9 de Julio de 2003.

9 Discurso en la Escuela de Guerra Naval de la Armada estadounidense, 20 de Junio de 2003. 
éxito cosechado en Afganistán, reforzó la injustificada autocomplacencia sobre los logros de una transformación que no había hecho más que empezar y obvió los inconvenientes que pudieron vislumbrarse en ambas campañas; sino que proporcionó una ilusoria sensación de confianza y ficticia seguridad que Estados Unidos pagaría poco después.

Efectivamente, la Operación Libertad Iraquí logró ocupar el país, tomar la capital y derrocar la dictadura de Saddam Hussein en pocas semanas. Sin embargo, ni el régimen baathista sucumbió al «choque y pavor» concebido por los estrategas del Pentágono, ni la manera en que se condujeron las operaciones militares fue tan revolucionaria como proclamaron los políticos y militares americanos, ni la oposición armada fue tan feroz como habían supuesto los generales de la coalición, ni la población recibió con los brazos abiertos a sus liberadores como había propugnado la oposición iraquí, ni la democracia floreció en el país y se propagó al resto de la región como habían imaginado los neoconservadores estadounidenses.

Igualmente, el reducido volumen de tropas empleado para invadir el país, su limitada preparación para el desempeño de labores de pacificación e incapacidad para controlar el territorio, el mantenimiento de grandes bolsas de resistencia, el convencimiento de que la comunidad internacional se sumaría a la estabilización y reconstrucción de Irak o la controvertida decisión de disolver el ejército y la policía iraquíes, provocaron el colapso total del país y el inicio de una profunda espiral de violencia. A fecha de hoy, el problema iraquí parece estar en vías de solución gracias al éxito logrado por la Doctrina Petraeus para controlar el territorio y reducir la violencia insurgente, el sostenido desarrollo de capacidades locales y la entrada en vigor del Acuerdo Sobre el Estatuto de Fuerzas según el cual la presencia militar americana se reducirá progresivamente hasta 2011, cuando está previsto que se transfiera la autoridad al gobierno iraquí y la salida definitiva de Estados Unidos del país.

\section{CONCLUSIÓN: LA NECESIDAD DE REVISAR LOS PILARES ESTRATÉGICOS DE ESTADOS UNIDOS}

Las campañas afgana e iraquí han permitido tanto evaluar la idoneidad de las decisiones estratégicas que las élites políticas y militares estadounidenses tomaron a lo largo de la inmediata posguerra fría como exponer las posibilidades y los límites del modelo militar que éstas trataron de desarrollar e implementar entre los años 1991 y 2001.

Aunque ambas campañas han vuelto a demostrar la imbatibilidad de Estados Unidos en el terreno convencional, una hegemonía que la RMA ha intensificado y que sin ninguna duda todos y cada uno de los competidores de Washington han tomado muy buena nota; Afganistán e Irak también han supuesto un baño de realismo que ha acabado con las proclamas revolucionarias de la década anterior y está obligando a revisar los pilares de la política de defensa y militar del país edificados años antes. 
En primer lugar, el mundo de hoy es muy distinto del que concibieron los estrategas estadounidenses cuando cayó el Telón de Acero. Y es que los trágicos acontecimientos de Septiembre de 2001 no sólo acabaron con el modelo de seguridad y defensa nacional de la inmediata posguerra fría y truncaron las ambiciones de la Administración Bush de alcanzar la anhelada RMA; sino que pusieron de manifiesto la total inadecuación de los ejes que guiaron el planeamiento estratégico de la inmediata posguerra fría para satisfacer los múltiples y complejos requerimientos del mundo del tercer milenio.

En segundo lugar, Afganistán e Irak han revelado las carencias del modelo militar americano que ideado en la Guerra Fría y ratificado tras el fin del mundo bipolar, se orienta a la consecución de victorias rápidas y decisivas mediante el empleo de una fuerza abrumadora. Aunque idóneo para preservar la gran estrategia de Estados Unidos (disuadir a cualquier adversario de iniciar un conflicto convencional contra el país; garantizar el acceso a cualquier teatro del planeta y para derrotar a cualquier competidor presente o futuro); este modelo ha mostrado su inadecuación para realizar operaciones de baja o media intensidad como pueden ser la estabilización, pacificación y reconstrucción de territorios hostiles en el contexto de operaciones contraterroristas y contrainsurgentes ${ }^{10}$.

En tercer lugar, estas campañas también han puesto de manifiesto el enorme coste político, humano, económico, material y diplomático que debe pagarse cuando se pretende el cambio forzoso de un régimen y su posterior pacificación... un coste que los acérrimos defensores de la RMA, con su fe ciega en la tecnología para lograr victorias rápidas, decisivas, sin apenas daños colaterales y prácticamente sin bajas propias, habían obviado en calcular.

Finalmente, estas guerras han demostrado, una vez más, las limitaciones inherentes de la tecnología para ver lo que sucede en el otro lado de la colina; el tradicional tecnocentrismo y latente convencionalismo del pensamiento militar americano, todavía articulado en torno al potencial de su industria y el poder de su armamento; la inmutable naturaleza de la guerra, en la que el horror, la destrucción, la violencia y la muerte son sus elementos definidores; y la equivocada dirección que tomó en un primer momento la transformación militar, inicialmente encaminada a conquistar la tan ansiada revolución y reforzar la supremacía del país frente a posibles competidores futuros y actualmente orientada a resolver los problemas presentes ${ }^{11}$.

${ }^{10}$ Estas y otras carencias han sido identificadas en el Concepto Básico para las Operaciones Conjuntas (Capstone Concept for Joint Operations) que, firmado por el Almirante Mike J. Mullen como máxima autoridad militar del país, orientará el desarrollo de nuevos conceptos operativos y la obtención de nuevas capacidades militares acordes con las necesidades militares actuales del país.

${ }^{11}$ Estas reflexiones están perfectamente resumidas por Frederick Kagan (2006: 253) al afirmar que: «...the U.S. Strategic Community in the 1990s was in general so caught up with the minutiae of technology that it lost sight of the larger purpose of war, and therefore missed the emergence of a challenge even more important than that of technology - the challenge of designing military operations to achieve particular political objectives. As it would turn out, that challenge would prove the most important for U.S. forces in the post-9/11 world.» 
En resumen, veinte años después del fin de la Guerra Fría, quince años después de que la Revolución Americana en los Asuntos Militares se situara en el centro del planeamiento de la defensa estadounidense y una década después de que las máximas autoridades políticas y militares del país diseñaran un ambicioso proceso de Transformación para conquistar la RMA; a fecha de hoy los principales responsables políticos y militares del país deben hacer frente a otros retos más urgentes (Cordesman, 2009). Planteados formalmente por la nueva Administración demócrata ${ }^{12}$, en los próximos años Estados Unidos deberá compaginar su salida de Afganistán e Irak con la adecuación de su estrategia defensiva al ambiente actual; la reconducción de su proceso de Transformación militar para dotar a sus fuerzas armadas de las capacidades necesarias para satisfacer las exigencias presentes; la determinación de un nivel de ambición, un catálogo de capacidades y un patrón de despliegue realistas y adecuados al entorno estratégico existente y previsible o la reforma de un sistema de programación de la defensa obsoleto, inflexible e incapaz de proporcionar las capacidades necesarias para satisfacer las necesidades actuales.

De tener éxito, este conjunto de transformaciones marcarán el final definitivo del paradigma estratégico de la inmediata posguerra fría y sentarán las bases del nuevo modelo de seguridad, defensa y militar de Estados Unidos para el mundo del siglo XXI.

12 A tal efecto, véase tanto el Informe de la Revisión Cuadrienal sobre los Roles y las Misiones (Quadrennial Roles and Missions Review Report) elaborado para guiar la articulación de la Revisión Cuadrienal de la Defensa 2010; el artículo publicado por el Secretario de Defensa Robert Gates en la prestigiosa revista Foreign Affairs en Enero de 2009; sus comparecencias ante el Comité del Senado para las Fuerzas Armadas los días 27 de Enero y 13 de Mayo de 2009; y la Revisión Cuadrienal de la Defensa presentada en Febrero de 2010. 


\section{BIBLIOGRAFÍA}

- BARDAJÍ, R. (2002). «Las dos guerras de Donald Rumsfeld», Política Exterior, 16, 1, 159-168

- BIDDLE, S. (2004). Afghanistan and the Future of Warfare: Implications for Army and Defense Policy, Carlisle, U.S. Army Strategic Studies Institute

- BINNENDIJK, H. (ed.) (2002). Transforming America's Military, Washington DC, National Defense University Press

- BOOT, M. (2003). «The New American Way of War», Foreign Affairs, 82, 4, 41-58

- BUSH, G. (2001). A Blueprint for New Beginnings, Washington DC, U.S. Government Printing Office

- Chairman of the Joint Chiefs of Staff (2009). Capstone Concept for Joint Operations, Washington DC: U.S. Government Printing Office

- _ _ (1996). Joint Vision 2010, Washington DC: U.S. Government Printing Office

- COHEN, E. (1996). «A Revolution in Warfare», Foreign Affairs, 75, 2, 37-56

- COLOM, G. (2008). Entre Ares y Atenea: el debate sobre la Revolución en los Asuntos Militares, Madrid, IUGGM-UNED

- CORDESMAN, A. (2009). Cleansing the Poisoned Chalice? The Obama Administration and The Challenge of National Security Planning, Programming and Budgeting, Washington DC, Center for Strategic \& International Studies

- FRIEDMAN, G. (1998). The Future of War: Power, Technology and American World Dominance in the Twenty-First Century, Nueva York, St. Martin's Griffin

- GALDI, T. (1995). Revolution in Military Affairs? Competing Concepts, Organizational Responses, Outstanding Issues, Congressional Research Service Report 95-1170F, Washington DC, U.S. Government Printing Office

- GATES, R. (2009). «A Balanced Strategy: Reprogramming the Pentagon for a New Age», Foreign Affairs, $89,1,6-18$

- GORDON, M. y TRAINOR, B. (2006). Cobra II, The Inside Story of the Invasion and Occupation of Iraq, Nueva York, Pantheon Books

- GRAY, C. (2006). Irregular Enemies and the Essence of Strategy: can the American Way of War Adapt?, Carlisle, U.S. Army Strategic Studies Institute

- _ (2002). Strategy for Chaos: Revolutions in Military Affairs and the Evidence of History, Londres, Routledge

- IKLÉ, A. y WOHLSTETTER, A. (eds.) (1988). Discriminate Deterrence, Washington DC, U.S. Government Printing Office 
- KAGAN, F. (2006). Finding the Target: The Transformation of American Military Policy, Nueva York, Encounter Books

- KITfIELD, J. (2005). War \& Destiny: How the Bush Revolution in Foreign and Military Affairs Redefined American Power, Washington DC, Potomac Books

- KNOX, M. y MURRAY, W. (eds.) (2001). The Dynamics of Military Revolution 1300-2050, Cambridge, Cambridge University Press

- $\quad$ LARSON, E., ORLETSKY, D. y LEUSCHNER, K. (2001). Defense Planning in a Decade of Change: Lessons from the Base Force, Bottom-Up Review, and Quadrennial Defense Review, Santa Monica, RAND Corporation

- LIPPITZ, M. y WHITE, J. (eds.) (2001). Keeping the Edge: Managing Defense for the Future, Cambridge, Preventive Defense Project

- O'HANLON, M. (1995). Defense Planning for the Late 1990s. Beyond the Desert Storm Framework, Washington DC, The Brookings Institution Press

- OWENS, W. (2000). Lifting the Fog of War, Nueva York, Farrar Straus \& Giroux

- $\quad$ RICKS, T. (2006). FIASCO, The American Military Adventure in Iraq. Nueva York, Penguin Press

- ROXBOROUGH, I. (2002). «From Revolution to Transformation, the State of the Field», Joint Forces Quarterly, 32, 68-76

- RUMSFELD, D. (2002). «Transforming the Military», Foreign Affairs, 81, 3, 20-32

- SHIMKO, K. (2010). The Iraq Wars and America's Military Revolution, Nueva York, Cambridge University Press

- WEIGLEY, R. (1977). The American Way of War, Bloomington, Indiana University Press

- WOODWARD, B. (2002). Bush at War. Nueva York, Simon \& Schuster 